\title{
Ferramentas tecnológicas para a escrita e a revisão de textos
}

\author{
Valéria da Costa Pinho \\ Colégio Pedro II (CP II) \\ Andrea de Farias Castro \\ Colégio Pedro II (CP II)
}

\begin{abstract}
Resumo
Este artigo tem como eixo principal o uso da tecnologia como ferramenta para auxiliar o trabalho de produção e revisão de textos com alunos do $3^{\circ}$ ano do ensino fundamental que apresentavam dificuldades na escrita de contos. As crianças leram e compararam dois textos com estruturas similares e produziram um terceiro a partir das análises que fizeram.
\end{abstract}

Palavras-chave: Educação, tecnologia educacional, produção de texto

\begin{abstract}
The main focus of this article is the use of technology as a tool to assist the production and proofreading of texts written by third-grade elementary school students who had presented difficulties in writing short stories. These children read and compared two texts that have similar structures and produced a third one based on the analyses that they did.
\end{abstract}

Key-words: Education, educational technology, text production

\section{INTRODUÇÃO}

Atualmente parece não se conceber mais a educação separada das novas tecnologias da informação e comunicação, as denominadas TICs. A tecnologia ocupa uma posição tão importante na sociedade atual que ela tem sido amplamente citada em documentos oficiais sobre educação.

No entanto, deve-se observar mais atentamente como as novas tecnologias estão chegando até a sociedade. Apesar de uma grande quantidade de pessoas não conseguir deixar de emitir mensagens digitais sobre si mesmas, muitas outras estão totalmente excluídas dessa nova era (BONILLA, 2009).

A escola, então, se vê na função de diminuir essas disparidades E o professor não pode mais ignorar essa invasão. É preciso saber trabalhar com as novas tecnologias, 
mas não a qualquer custo: é preciso ter segurança em relação aos recursos que se deseja utilizar e ter clareza dos objetivos que se quer alcançar.

Este trabalho, portanto, tem o objetivo de relatar uma experiência com um software para a escrita e revisão de textos com alunos do $3^{\circ}$ ano dos anos iniciais do ensino fundamental.

Em primeiro lugar, será feita uma distinção entre os termos técnica e tecnologia e um histórico sobre o uso desses termos ao longo do tempo. Depois se farão alguns esclarecimentos sobre as habilidades que precisam ser desenvolvidas para a escrita de contos. E, por fim, haverá a narrativa de uma experiência de trabalho com o software Story Book Weaver $^{1}$ para escrita e revisão de textos com crianças, em uma tentativa de mostrar que o uso da tecnologia na escola precisa estar aliado a objetivos claros do planejamento do professor e a oportunidade de acesso de todos aos saberes criados pela sociedade.

\section{O QUE É TECNOLOGIA?}

Antes de responder a esta pergunta, é preciso fazer a distinção entre técnica e tecnologia. A palavra técnica tem sua origem no verbo grego tictein, que significa “criar, produzir, conceber, dar à luz” (LION, 1997, p. 24). Técnica era um termo amplo que abrangia não só as ferramentas e matérias-primas, mas também a pessoa que elaborava e produzia um produto. Na Grécia antiga, as palavras arte e técnica andavam juntas e a separação entre elas era pequena. Mais tarde, na Revolução Industrial, o produto e sua produção ficaram à frente da pessoa. Produzidos em larga escala, os produtos surgiam exatamente iguais, sem qualquer distinção entre eles, sem a marca individual do seu produtor. Assim a arte se separou da técnica que, por sua vez, se reduziu aos instrumentos. A técnica, então, passou a ser definida como “[...] um conhecimento empírico, que, graças à observação, elabora um conjunto de receitas e práticas para agir sobre as coisas" (CHAUÍ, 1997, p. 222). Assim, a partir de conhecimentos da vida prática criaram-se instrumentos técnicos para aumentar a capacidade do homem para lidar com a natureza.

\footnotetext{
${ }^{1}$ O software Story Book Weaver foi produzido em 1994 pela MECC, com a finalidade de estimular a autoria e ilustração de histórias por crianças na faixa etária entre 6-12 anos. O produto contém inúmeras imagens, cenários e personagens. Permite também a escrita do texto em inglês, português e espanhol.
} 
No entanto, ao unir a técnica ao saber, à ciência, o homem se fez presente novamente, criando a tecnologia que "configura-se como um corpo de conhecimentos que, além de usar o método científico, cria e/ou transforma processos naturais" (SANCHO, 1998, p. 29). Para Lion (1997, p. 26) "a tecnologia se estende como o uso do conhecimento científico para especificar modos de fazer as coisas de maneira reproduzível”. A tecnologia seria um saber teórico que se aplica na prática de forma a intervir na natureza ou até mesmo de controlá-la.

O termo tecnologia trouxe consigo alguns mitos oriundos do termo ciência. Devido à forte ligação entre as duas palavras, o termo tecnologia herdou ideias equivocadas (LION, 1997) como neutralidade, linearidade e continuidade. Herdou também a ideia de que o acúmulo de conhecimentos levava sempre ao progresso. No entanto, a história nos mostra que a ciência nem sempre é linear e contínua, algumas vezes ela caminha por saltos e rupturas como no caso de Copérnico que rompeu com as teorias de Ptolomeu, retirando a Terra do centro do universo. Já o acúmulo de conhecimento e a tecnologia trouxeram o progresso para uma parte da população, mas não para a totalidade. Para alguns a tecnologia traz a fertilização in vitro, enquanto para outros não há acesso sequer ao saneamento básico. Desigualdades que aumentam à medida que novos conhecimentos surgem em grande velocidade.

Entender o termo tecnologia não é só conhecer sua definição, mas é também entender seu histórico e perceber as ideias (equivocadas ou não) que circundam essa palavra.

Portanto, o objetivo deste relato de experiência é mostrar a tecnologia como ferramenta de trabalho para facilitar a aprendizagem dos alunos. Ferramenta que deve ser de domínio do professor para que ele possa buscar adequá-la aos objetivos a que se propõe e que deve ser usada como forma de inclusão.

\section{O SUPORTE TECNOLÓGICO PARA A ESCRITA DE TEXTOS}

A competência de escrever um texto exige do aluno várias habilidades como saber as características do texto escolhido (conto, carta, e-mail, poesia, relato de experiência e outros), escrever as palavras corretamente, usar a pontuação adequada, escrever com coerência (fazendo a articulação entre começo, meio e fim do texto, sem 
fugir do tema proposto) e coesão (evitando a repetição de palavras e buscando conectivos para ligar as frases e parágrafos). Enfim, não é tarefa fácil, nem para escritores experientes. Por isso, então, a necessidade de variar as atividades para que os alunos possam ter experiências diferenciadas que enriqueçam seu repertório de escrita.

Além da escrita, é preciso que os alunos aprendam a corrigir seus textos para reescrevê-los, pois é assim que os escritores fazem: eles escrevem, reescrevem, retiram trechos, acrescentam outros, fazem uma revisão, enviam seu texto para que outra pessoa faça mais uma revisão e somente depois de todas essas etapas é que publicam o material. Por que, então, pensar que os alunos devem escrever de uma só vez corretamente? No entanto, para as crianças pequenas, apagar e reescrever demanda muito tempo, o que acaba gerando desinteresse pela atividade.

Por isso, então, resolvemos trabalhar com um programa de edição de texto que facilitasse a escrita e a revisão das produções dos alunos: o programa escolhido foi o Story Book Weaver, criado para a produção de história em formato de livros. Ele é de fácil manuseio tanto para professores quanto para alunos porque sua interface é muito simples. A primeira tela do programa serve para a confecção da capa do livro onde se pode colocar uma borda decorativa, o título e figuras sobre o tema abordado. As telas seguintes simulam as próximas páginas do livro. Nessas telas é possível compor um cenário, na parte superior da página, incluindo pessoas, veículos e objetos em geral. Há várias opções de cenários e figuras para compô-los. É possível também aumentar e diminuir o tamanho das figuras, mudar suas cores e alterar suas direções. A escrita do texto é feita na parte inferior da página. $\mathrm{O}$ texto também pode ser composto de vários tipos e tamanhos de letras. Apesar de ser um programa um pouco antigo, fizemos esta escolha por entendermos que é preciso que o professor tenha segurança em trabalhar com a ferramenta selecionada, sendo, sobretudo, uma opção que ajude a alcançar os objetivos de aprendizagem propostos.

Os alunos escolhidos para o trabalho foram crianças do $3^{\circ}$ ano dos anos iniciais do Colégio Pedro II que apresentavam dificuldades na elaboração de textos escritos: dificuldades tanto na ortografia, quanto na pontuação e na coerência. Talvez, por isso, também não demonstrassem interesse pelas atividades de escrita e procurassem realizálas de forma mais breve possível. 
Os objetivos da atividade eram, usando o programa Story Book Weaver (SBW), escrever uma história a partir de outras histórias semelhantes, já lidas e interpretadas em sala; fazer a revisão da escrita do texto; ler e reproduzir a história para os outros colegas de turma.

As atividades foram divididas em seis aulas de dois tempos por semana cada uma. Na primeira aula realizou-se a leitura e interpretação do texto "A roupa nova do rei” que traz a história de dois malandros que se passam por alfaiates e enganam o rei dizendo que somente as pessoas inteligentes poderiam ver a linda roupa que eles costuravam. No final da história, apenas uma criança tem a coragem de revelar que os alfaiates não produziram nada. Os alunos fizeram, inicialmente, uma leitura silenciosa. Depois cada um leu um trecho em voz alta e logo após, então, fizeram a caracterização dos personagens, do espaço e do tempo onde se passava a história. Por fim, concluíram qual era a lição que o conto pretendia ensinar.

Na segunda aula, os alunos leram o conto "Tyll, o mestre das artes" que é a história de um malandro que se passa por pintor e engana o rei e todos os súditos, dizendo que só as pessoas inteligentes poderiam ver seus quadros. No final da história, a empregada é a única que tem coragem de dizer que nada foi pintado pelo malandro. Os alunos, então, cumpriram as mesmas etapas realizadas para o conto anterior. Propusemos, então, que as crianças comparassem os dois contos. Elas descobriram semelhanças entre eles e listaram os seguintes pontos em comum: um rei orgulhoso, malandros que enganavam o rei, súditos que fingiam ver o que não existia para não se passarem por imbecis e uma pessoa simples que desmascarava a farsa.

$\mathrm{Na}$ terceira aula, relembrando os pontos de interseção entre os dois contos, propusemos aos alunos que imaginassem um conto com características semelhantes. A resposta foi rápida: disseram que não queriam escrever, que era muito chato. Essa é uma reação comum entre crianças que apresentam dificuldades na escrita, afinal como ter prazer em uma atividade considerada difícil e que, muitas vezes, não tem um objetivo claro para que seja cumprida? Nem sempre os alunos escrevem algo para ser lido, muitas vezes o que escrevem é apenas para ser corrigido. Nem sempre há uma resposta ou comentário sobre seus textos, algumas vezes há apenas um visto (LEAL, 2008, p. 55). Sendo assim, o resultado não poderia ser outro além do desinteresse e da negativa em realizar a tarefa. 
Dissemos às crianças que, depois de pronto, o texto seria lido para os outros colegas da série e que seria reproduzido para turma. Nesse momento houve uma reação de surpresa e até de alguma satisfação, já que apresentar um texto da própria autoria aos colegas traz um destaque que muitas vezes as crianças não experimentam devido às dificuldades do dia a dia. É importante evidenciar para as crianças que a escrita tem um destinatário; que, quando se escreve, se escreve para alguém e com algum objetivo. (ROCHA, 2008, p. 71). Por fim, informamos a elas que a atividade seria realizada na sala de informática para que pudesse ser digitada e impressa.

$\mathrm{Na}$ quarta aula, fomos para a sala de informática e apresentamos aos alunos o programa Story Book Weaver e suas funcionalidades. Falamos sobre a escrita em capítulos, as possibilidades de ilustração com diferentes cenários e personagens. Deixamos, então, que explorassem os recursos do programa como a mudança de posição das figuras, o aumento ou diminuição de tamanho de objetos selecionados, os variados cenários, os diferentes tipos e tamanhos de fontes.

Após essa etapa inicial, relembramos a eles qual era nosso objetivo em usar o programa e qual era a proposta de trabalho: escrever um conto com características parecidas com as dos contos lidos anteriormente. Assim começaram a montar o cenário da história que escreveriam. É importante destacar que se a tarefa fosse feita em sala de aula, primeiro os alunos escreveriam o texto e depois fariam o desenho. No entanto, a montagem do cenário a priori ajudou na formulação do encadeamento da história e na escolha dos personagens.

Buscar maneiras diferentes de trabalhar atividades do cotidiano oportuniza ao professor observar seus alunos por novos ângulos. Ficamos surpresas ao ver o comportamento diferente que uma menina apresentou durante a atividade: em sala de aula, ela era muito calada, tinha vergonha de mostrar o que escrevia e participava pouco das atividades, mas, diante do computador, ficou muito à vontade. O programa já era conhecido pela aluna que, inclusive, deu dicas para os colegas, além de ter ficado visivelmente interessada na tarefa. Outros alunos que também se mostravam desinteressados durante as aulas tiveram uma postura diferente e queriam dividir com os colegas as ideias que surgiam para a história e as descobertas sobre como usar o programa. 
$\mathrm{Na}$ quinta aula, começamos a fazer a revisão do texto, entendendo que essa tarefa é uma maneira de ver o texto em outra perspectiva, já que na primeira versão do trabalho, o aluno está preocupado com questões como:

o que dizer, como dizer, que palavras usar... Durante o processo de revisão, o aluno tem a possibilidade de centrar seus esforços em questões pertinentes ao plano textual discursivo, como dizer mais, dizer de outro jeito, analisar e/ou corrigir o que foi dito... (ROCHA, 2008, p. 73).

Então, enquanto algumas crianças ainda terminavam de escrever suas histórias, começamos a fazer a revisão da paragrafação e da coerência do texto com cada aluno. Cabe ressaltar que o nosso objetivo nessa atividade não era de apenas corrigir o trabalho da criança, mas também de ajudá-la a perceber os problemas do texto para que ela mesma pudesse saná-los. Também é preciso destacar que o editor de texto do programa facilita bastante a tarefa da correção que no caso do lápis e papel causa muito aborrecimento.

$\mathrm{Na}$ sexta aula fizemos a revisão da ortografia das palavras e da pontuação das frases. Primeiro, as crianças trocaram de computador entre si e cada uma leu a história da outra para tentar corrigir o que conseguiam perceber. Depois sublinhamos palavras que não haviam sido corrigidas para que elas as procurassem em um dicionário on-line. Por fim, fomos indicando algumas frases que ainda não estavam pontuadas corretamente. Nesse momento alguns alunos também perceberam incoerências no cenário de um capítulo para o outro da história e as distorções foram corrigidas. Essa foi uma parte interessante da revisão para a qual não havíamos atentado anteriormente. Ao fazermos um conto em capítulos com cenários, esses cenários precisam ter um encadeamento de uma parte para outra da história. Deve haver uma coerência tanto no texto quanto nas imagens.

Para ilustrar melhor os resultados deste trabalho, colocaremos aqui algumas ideias que os alunos tiveram para os seus contos: 


\begin{tabular}{|c|c|c|c|c|}
\hline Aluno: & $\begin{array}{c}\text { Pessoa que foi } \\
\text { enganada: }\end{array}$ & Malandro(a): & A farsa: & $\begin{array}{c}\text { Quem } \\
\text { descobre a } \\
\text { verdade: }\end{array}$ \\
\hline $\begin{array}{c}\text { Aluno } \\
\text { A }\end{array}$ & $\begin{array}{c}\text { O técnico de } \\
\text { futebol }\end{array}$ & $\begin{array}{c}\text { Jogador de } \\
\text { futebol }\end{array}$ & $\begin{array}{c}\text { Somente as pessoas } \\
\text { inteligentes poderiam } \\
\text { ver a bola com qual } \\
\text { o malandro fazia seus } \\
\text { gols. }\end{array}$ & $\begin{array}{c}\text { Um torcedor } \\
\text { que estava na } \\
\text { arquibancada. }\end{array}$ \\
\hline $\begin{array}{c}\text { Aluno } \\
\text { B }\end{array}$ & $\begin{array}{c}\text { Um freguês da } \\
\text { carrocinha de } \\
\text { cachorro-quente }\end{array}$ & $\begin{array}{c}\text { Vendedor de } \\
\text { cachorro- } \\
\text { quente }\end{array}$ & $\begin{array}{c}\text { Somente as pessoas } \\
\text { inteligentes poderiam } \\
\text { ver a salsicha no pão. }\end{array}$ & Outro freguês \\
Cluno & $\begin{array}{c}\text { O presidente } \\
\text { dos Estados } \\
\text { Unidos }\end{array}$ & $\begin{array}{c}\text { Vendedor de } \\
\text { livros }\end{array}$ & $\begin{array}{c}\text { Somente as pessoas } \\
\text { inteligentes poderiam } \\
\text { ver os maravilhosos } \\
\text { livros que estavam } \\
\text { em uma linda caixa. }\end{array}$ & $\begin{array}{c}\text { O motorista } \\
\text { do presidente }\end{array}$ \\
\hline Aluno & $\begin{array}{c}\text { O cantor Justin } \\
\text { Bieber }\end{array}$ & A cantora & $\begin{array}{c}\text { Somente as pessoas } \\
\text { inteligentes poderiam } \\
\text { ver os ponteiros de } \\
\text { um relógio caríssimo. }\end{array}$ & A empregada \\
do cantor
\end{tabular}

É interessante notar as ideias originais que ocorreram aos alunos que inicialmente se recusaram a escrever. Esses resultados sinalizam que um planejamento criterioso aliado a ferramentas tecnológicas pode colaborar não só com o aprendizado dos conteúdos programáticos, mas também com o interesse dos alunos pela realização das atividades.

\section{CONSIDERAÇÕES FINAIS}

O foco deste trabalho foi apresentar reflexões sobre uma atividade que envolveu o desenvolvimento da escrita e revisão de texto com o uso de um software para a edição de texto com crianças do $3^{\circ}$ ano de escolaridade dos anos iniciais.

A análise e distinção dos vocábulos técnica e tecnologia, indicando a origem dessas palavras e os significados que elas carregam até os dias atuais contribuiu para esclarecer que o conhecimento precisa estar revestido de um cunho social para que o progresso alcance a todos.

Por fim, a apresentação de uma atividade que implicou análise e produção de novos produtos pelas crianças participantes ajudou-nos a perceber que usar uma 
ferramenta tecnológica para estimular e facilitar a aprendizagem dos alunos não foi uma opção apenas por uma nova técnica de trabalho. Foi, antes, a opção por uma visão diferenciada sobre a função do professor no processo educacional. Visão que enxerga o professor como profissional capaz de buscar novos caminhos para o trabalho cotidiano e de aprender junto com seus alunos a lidar com a avalanche de novos conhecimentos que chegam a todo o momento.

\section{REFERÊNCIAS}

BONILLA, M. H. S. (2009). Escola aprendente: comunidade em fluxo. In: FREITAS, M. T. D. A. (org.). Cibercultura e formação de professores. Belo Horizonte: Autêntica, P. 23-56.

CHAUÍ, M. (1997). Convite à filosofia. São Paulo: Ática.

LEAL, L. D. F. V. (2008). A formação do produtor de texto escrito na escola: uma análise das relações entre os processos interlocutivos e os processos de ensino. In: VAL, M. D. G. C.; ROCHA, G. (orgs.). Reflexões sobre práticas escolares de produção de text. Belo Horizonte: Autêntica, 2008. P. 53-67.

LION, C. G. (1997). Mitos e realidades na tecnologia educacional. In: LITWIN, E. (org.). Tecnologia educacional: política, histórias e propostas, 3. Porto Alegre: ArtMed, P. 23-36.

ROCHA, G. (2008). O papel da revisão na apropriação de habilidades textuais pela criança. In: VAL, M. D. G. C.; ROCHA, G. (orgs.) Reflexões sobre práticas escolares de produção de texto. Belo Horizonte: Autêntica, P. 69-83.

SANCHO, J. M. (1998). A tecnologia: um modo de transformar o mundo carregado de ambivalência. In: SANCHO, J. M. Para uma tecnologia educacional, 1. Porto Alegre: ArtMed, P. 23-49.

\section{AS AUTORAS}

Valéria da Costa Pinho é professora dos anos iniciais do Colégio Pedro II. Possui Licenciatura em Matemática e é mestranda do Programa de Pós-Graduação em Práticas de Educação Básica do Colégio Pedro II.

E-mail: valeriacpinho@gmail.com 
Andrea de Farias Castro é professora do curso de Mestrado Profissional em Práticas de Educação básica do Colégio Pedro II e do Instituto Multidisciplinar de Formação Humana com Tecnologias da UERJ. Doutora em Educação pela UERJ e especialista em Docência Superior e Informática Educativa.

E-mail: prof.andreacastro@gmail.com 